\title{
Uso de metodologias ativas no ensino de enfermagem durante a pandemia pelo
}

\section{COVID-19: uma revisão integrativa}

\author{
Use of active methodologies in nursing teaching during the pandemic by COVID-19: an integrative \\ review
}

Uso de metodologías activas en la enfermería durante la pandemia por COVID-19: una revisión integradora

\author{
Ana Luiza Souza de Faria Lôbo \\ ORCID: https://orcid.org/0000-0002-8877-0338 \\ Universidade Federal de Alagoas, Brasil \\ E-mail: analuizalobo91@gmail.com \\ Amuzza Aylla Pereira dos Santos \\ ORCID: https://orcid.org/0000-0001-6299-7190 \\ Universidade Federal de Alagoas, Brasil \\ E-mail:amuzza.pereira@eenf.ufal.br \\ Isabel Comassetto \\ ORCID: https://orcid.org/0000-0002-2389-9384 \\ Universidade Federal de Alagoas, Brasil \\ E-mail: isabel.comassetto@eenf.ufal.br \\ Mariana Maria Pereira Cintra Farias \\ ORCID: https://orcid.org/0000-0001-5041-5376 \\ Universidade Federal de Alagoas, Brasil \\ E-mail: maripcintra@gmail.com \\ Nathalia Lima da Silva \\ ORCID: https://orcid.org/0000-0002-5163-7103 \\ Universidade Federal de Alagoas, Brasil \\ E-mail: nathalialimaa17.nl@gmail.com
}

\begin{abstract}
Resumo
O objetivo deste artigo investigar o que tem sido produzido sobre Metodologias ativas em tempos de pandemia, no contexto do ensino em Enfermagem, através de uma revisão integrativa de literatura. Metodologia: trata-se de um estudo qualitativo, com abordagem descritiva e retrospectiva, realizado através de uma revisão integrativa da literatura, estudo com coleta de dados realizada a partir de fontes secundárias, no período de junho de 2021. Resultados: utilizando a Biblioteca Virtual em Saúde (BVS) foram selecionados 05 para compor a amostra deste estudo. Sendo assim, destacamos que 3 eram estudos em português e 2, em inglês. O período de publicação entre 2020 e 2021. Discussão: após análise dos artigos surgiram duas categorias para melhor apresentação do conteúdo. Sendo elas: Utilização de metodologias ativas, estratégias de ensino e tecnologias no contexto de pandemia; e Desafios e obstáculos da modalidade remota para o ensino em Enfermagem durante a pandemia. Conclusão: é notório que o tema é uma crescente entre o meio acadêmico, pois envolve discente e docentes, que são peças fundamentais para aplicação e melhoria da metodologia a ser utilizada em sala de aula virtual.
\end{abstract}

Palavras-chave: Metodologia; Ensino; Enfermagem; COVID-19.

\begin{abstract}
The aim of this article is to investigate what has been produced about Active Methodologies in times of pandemic, in the context of Nursing education, through an integrative literature review. Methodology: this is a qualitative study, with a descriptive and retrospective approach, carried out through an integrative literature review, a study with data collection carried out from secondary sources, in the period of June 2021. Results: using the Virtual Health Library (VHL) 05 were selected to compose the sample of this study. Therefore, we highlight that 3 were studies in Portuguese and 2 in English. The period of publication between 2020 and 2021. Discussion: after analyzing the articles, two categories emerged to better present the content. These are: Use of active methodologies, teaching strategies and technologies in the context of a pandemic; and Challenges and obstacles of the remote modality for teaching Nursing during the pandemic. Conclusion: it is notorious that the theme is a growing one among the academic world, as it involves students and teachers, who are fundamental parts for the application and improvement of the methodology to be used in the virtual classroom.
\end{abstract}

Keywords: Methodology; Teaching; Nursing; COVID-19. 


\begin{abstract}
Resumen
El objetivo de este artículo es investigar lo producido sobre Metodologías Activas en tiempos de pandemia, en el contexto de la formación en Enfermería, a través de una revisión integradora de la literatura. Metodología: se trata de un estudio cualitativo, con enfoque descriptivo y retrospectivo, realizado a través de una revisión integradora de la literatura, estudio con recolección de datos de fuentes secundarias, en el período de junio de 2021. Resultados: utilizando la Biblioteca Virtual en Salud (BVS) se seleccionaron 05 para componer la muestra de este estudio. Por tanto, destacamos que 3 fueron estudios en portugués y 2 en inglés. El período de publicación entre 2020 y 2021. Discusión: después de analizar los artículos, surgieron dos categorías para presentar mejor el contenido. Estos son: Uso de metodologías activas, estrategias de enseñanza y tecnologías en el contexto de una pandemia; y retos y obstáculos de la modalidad remota para la docencia de Enfermería durante la pandemia. Conclusión: es notorio que el tema es un tema creciente en el mundo académico, ya que involucra a estudiantes y docentes, quienes son piezas fundamentales para la aplicación y mejora de la metodología a utilizar en el aula virtual.
\end{abstract}

Palabras clave: Metodología; Enseñando; Enfermería; COVID-19.

\title{
1. Introdução
}

O novo Coronavírus (SARS-CoV-2) possui elevada taxa de transmissão e letalidade, tornando-se uma emergência de saúde pública de interesse internacional em 30 de janeiro de 2020. Em 13 de março de 2020, a Organização Mundial de Saúde decidiu decretar pandemia devido ao aumento exponencial do número de casos de Coronavírus e sua disseminação global (de Souza Junior et al, 2020).

Diante da pandemia e seguindo as orientações sanitárias quanto a necessidade de isolamento, as Instituições de Ensino de vários estados brasileiros interromperam as atividades acadêmicas presenciais, com base na discussão da transmissibilidade por aglomerações, promovendo desse modo, o distanciamento social entre a comunidade acadêmica (alunos, professores, e demais funcionários) (Oliveira et al, 2020). Desta forma, passou-se a requerer dessas instituições, bem como dos docentes, que saíssem das suas zonas de conforto para começarem a caminhar por novas estratégias de ensino/aprendizagem e aplicassem as diferentes formas através de ambiente digital (Oliveira et al, 2020).

As Metodologias Ativas (MA) são fundamentais para o funcionamento e adequação das aulas em tempos de pandemia, de modo que todos envolvidos necessitam estar atentos para o crescimento das inovações tecnológicas que condicionam as transformações sociais, mostrando assim o impacto positivo no processo de ensino (Oliveira et al, 2020). A MA tem por objetivo tornar o discente um ser proativo, criativo e sujeito ativo do próprio aprendizado, para isso, é preciso envolvê-lo em atividades básicas e complexas para que aprendam e tenham a liberdade de tomar decisões e avaliá-las, com base em seu conhecimento, demonstrando assim a criatividade (Macedo et al, 2018).

A pandemia Covid-19 mostrou que além do uso das tecnologias, fator de suma importância, visto a situação de distanciamento social, é necessário ter disposição para aplicar o pensamento crítico, principalmente na formação em enfermagem, com a finalidade de garantir o desenvolvimento das competências essenciais à prática do enfermeiro (Riegel et al., 2021).

Assim, o objetivo deste artigo é investigar o que tem sido produzido sobre Metodologias ativas em tempos de pandemia, no contexto do ensino em Enfermagem, através de uma revisão integrativa de literatura.

\section{Metodologia}

Trata-se de um estudo qualitativo, com abordagem descritiva e retrospectiva, realizado através de uma revisão integrativa da literatura, estudo com coleta de dados realizada a partir de fontes secundárias, por meio de levantamento bibliográfico, buscando-se semelhanças e diferenças entre os artigos levantados nos documentos de referências.

As fases iniciais do estudo seguiram as etapas recomendadas por Gil (2010), tais como a escolha do tema, levantamento da literatura preliminar, formulação do problema de pesquisa e elaboração dos objetivos. Quanto aos aspectos éticos, por se tratar de um estudo utilizando como fonte os dados secundários coletados através de bases de dados indexadas, essa pesquisa não 
necessitou ser submetida ao Comitê de Ética em Pesquisa com seres humanos (CEP) conforme a Resolução nº 510 , de 7 de abril de 2016.

$1^{a}$ etapa - Identificação do problema ou delimitação da pergunta condutora do estudo: a pergunta norteadora da pesquisa foi: Como ocorreu o uso das metodologias ativas no ensino em enfermagem durante o período de pandemia pela COVID-19?

$2^{\mathrm{a}}$ etapa - Amostragem ou busca na literatura: Para o levantamento dos artigos na literatura foi realizada uma busca em bases de dados indexadas. Serão utilizados, para a busca dos artigos, os seguintes descritores: "Metodologia"; "Ensino", "Enfermagem" e "COVID-19" com a utilização do operador booleano “AND” na Biblioteca Virtual de Saúde.

Os critérios de inclusão foram: produção científica sobre a temática, artigos indexados nas bases de dados, com acesso on-line, publicados no período de pandemia pela COVID-19 (2020-2021); publicações em português, inglês e espanhol. Foram excluídos os editoriais, resumos de pesquisas e artigos de jornal que não apresentavam caráter científico.

$3^{\text {a }}$ etapa - Categorização dos estudos ou coleta de dados: a coleta de dados ocorreu no período de junho (2021) e para que fosse efetiva foi elaborada com base no modelo proposto por Ursi (2005) e adaptado às especificidades deste estudo, de modo a dar visibilidade aos principais atributos de cada produção. Este modelo foi adaptado para conter os seguintes itens: título, autores, periódico e ano de publicação, idioma, objetivos, resultados e conclusões.

4 etapa - Análise de dados: A análise e síntese dos estudos foram realizadas de forma descritiva, possibilitando observar, contar e descrever os dados, com o intuito de reunir o conhecimento produzido sobre o tema explorado na revisão, de modo que o objetivo a ser alcançado possa contribuir de forma positiva com as evidências disponíveis acerca da utilização das metodologias ativas no ensino em Enfermagem durante o período de pandemia.

$5^{\text {a }}$ etapa - Interpretação e discussão dos dados: Nesta etapa ocorreu a comparação dos dados evidenciados na análise dos artigos.

$6^{\mathbf{a}}$ etapa - Apresentação da revisão integrativa: apresentação da pesquisa em formato de artigo científico.

\section{Resultados}

Durante a coleta de dados, com utilização dos descritores citados anteriormente, na plataforma da Biblioteca Virtual em Saúde (BVS) foram encontrados 78 artigos, dos quais, após a leitura dos títulos e seus respectivos resumos foram selecionados 05 para compor a amostra deste estudo. É importante ressaltar que a maioria dos artigos encontrados e que não compuseram a amostra, relacionam-se sobretudo aos desafios do ensino remoto no cenário de calamidade pública instalado pela pandemia por COVID-19, não elencando questões acerca da utilização de metodologias ativas. A Figura 1 abaixo demonstra o fluxograma representativo da coleta de dados da pesquisa. 
Figura 1: Fluxograma representativo da coleta de dados da pesquisa.

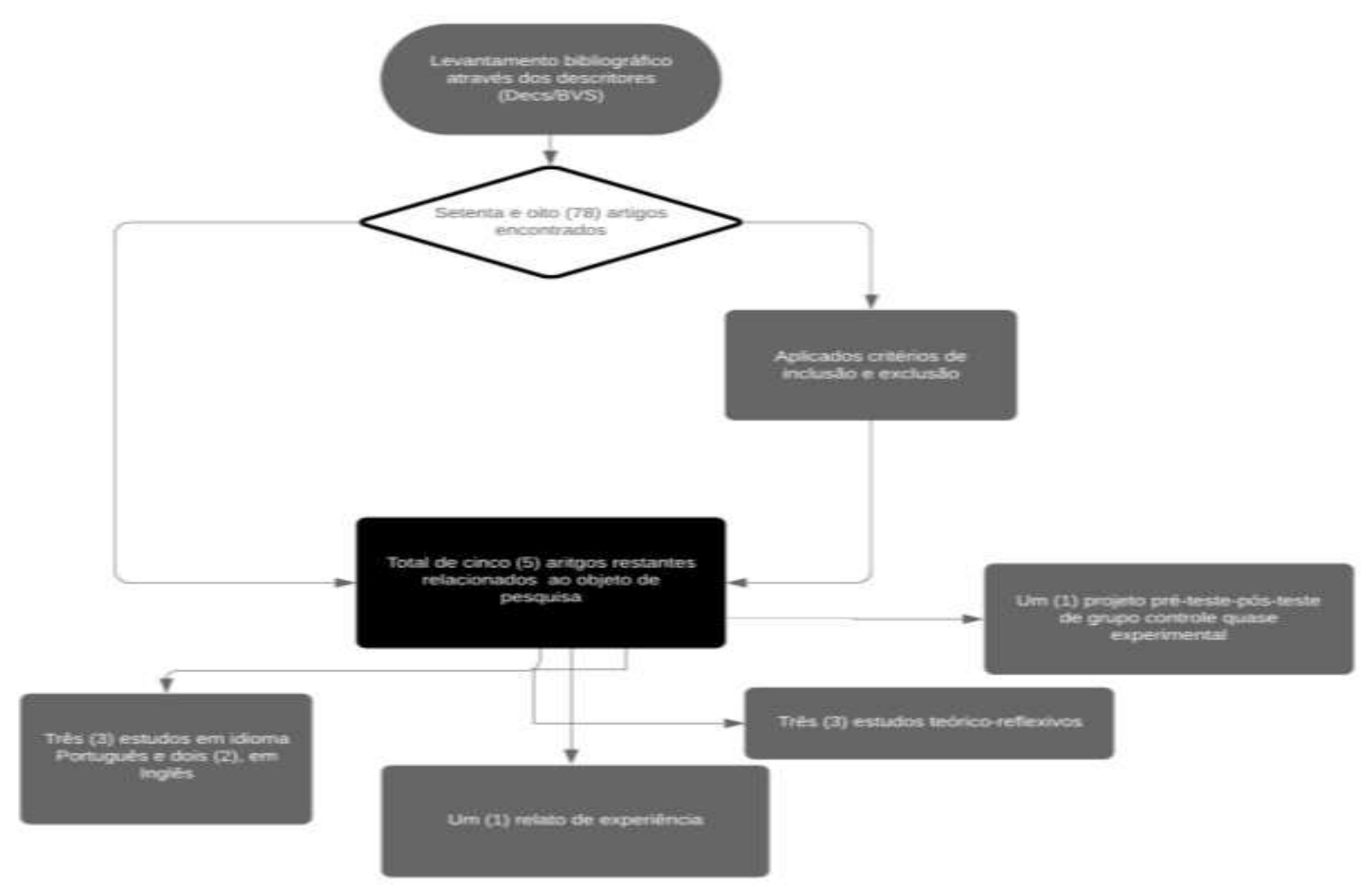

Fonte: Dados da pesquisa (2021).

Sendo assim, dos 05 artigos selecionados, destacamos que 3 eram estudos em português e 2, em inglês, sendo 3 estudos teóricos reflexivos, 01 relato de experiência e 01 projeto de pré-teste-pós-teste de grupo de controle quase experimental. Dos quais, ambos se associaram à temática abordada no estudo. O Quadro 1 abaixo descreve os artigos selecionados na pesquisa.

Quadro1: Identificação dos artigos selecionados, autores, periódicos e ano de publicação, objetivos, resultados e conclusões.

\begin{tabular}{|c|c|c|c|c|c|c|}
\hline $\begin{array}{c}\text { TÍTULO DO } \\
\text { ARTIGO }\end{array}$ & AUTORES & $\begin{array}{c}\text { PERIÓDICO E } \\
\text { ANO DE } \\
\text { PUBLICAÇÃO }\end{array}$ & IDIOMA & OBJETIVOS & RESULTADOS & CONCLUSÕES \\
\hline $\begin{array}{l}\text { Pandemia da } \\
\text { COVID-19, } \\
\text { ensino } \\
\text { emergencial a } \\
\text { distância e } \\
\text { Nursing Now: } \\
\text { desafios à } \\
\text { formação em } \\
\text { enfermagem }\end{array}$ & $\begin{array}{c}\text { Silva, C.M. } \\
\text { Toriyama, } \\
\text { A.C.M., Claro, } \\
\text { H.G., Borghi, } \\
\text { C.A., Castro, } \\
\text { T.J. \& } \\
\text { Salvador, } \\
\text { P.I.C.A. }\end{array}$ & $\begin{array}{l}\text { Rev Gaúcha } \\
\text { Enferm. } 2021\end{array}$ & Português & $\begin{array}{c}\text { Discutir as } \\
\text { atividades não } \\
\text { presenciais no } \\
\text { ensino de } \\
\text { enfermagem, no } \\
\text { contexto da } \\
\text { pandemia da } \\
\text { COVID-19 e em } \\
\text { meio à } \\
\text { campanha } \\
\text { "Nursing Now" } \\
\text { pelo } \\
\text { fortalecimento } \\
\text { da enfermagem }\end{array}$ & $\begin{array}{c}\text { Foi realizado um estudo } \\
\text { teórico-reflexivo pautado na } \\
\text { discussão acerca do isolamento } \\
\text { por COVID-19, da } \\
\text { implementação do ensino } \\
\text { emergencial } \\
\text { a distância e das implicações } \\
\text { para a qualidade da formação } \\
\text { do enfermeiro, destacada como } \\
\text { prioridade pela campanha } \\
\text { Nursing Now. Ressaltaram os } \\
\text { impactos negativos das } \\
\text { dificuldades na qualidade de } \\
\text { ensino, acesso desigual e falta } \\
\text { de preparo docente. No que se } \\
\text { refere aos desafios dos } \\
\text { docentes, os autores sinalizam } \\
\text { uma crítica quanto ao emprego } \\
\text { de tecnologias digitais e } \\
\text { conhecimento sobre o EaD pra } \\
\text { manter o ensino da } \\
\text { Enfermagem }\end{array}$ & $\begin{array}{c}\text { Destacam-se prejuízos na } \\
\text { formação dos enfermeiros } \\
\text { no ensino emergencial a } \\
\text { distância, em contraste } \\
\text { com o } \\
\text { movimento mundial pela } \\
\text { valorização da } \\
\text { enfermagem. Ressaltam } \\
\text { que o estudante de } \\
\text { enfermagem não pode ser } \\
\text { reduzido a um consumidor } \\
\text { de conteúdo a distância, } \\
\text { reforçando a importante da } \\
\text { utilização adequada de } \\
\text { tecnologias direcionadas a } \\
\text { um movimento de } \\
\text { autonomia, colaboração e } \\
\text { construção coletiva. }\end{array}$ \\
\hline
\end{tabular}




\begin{tabular}{|c|c|c|c|c|c|c|}
\hline $\begin{array}{l}\text { Desenvolvendo o } \\
\text { pensamento } \\
\text { crítico no ensino } \\
\text { de Enfermagem: } \\
\text { um desafio em } \\
\text { tempos de } \\
\text { pandemia de } \\
\text { Covid-19 }\end{array}$ & $\begin{array}{l}\text { Riegel, F., } \\
\text { Martini, JG., } \\
\text { Bresolin, P., } \\
\text { Mohallem, } \\
\text { A.G.C. \& Nes } \\
\text { A.A.G. }\end{array}$ & $\begin{array}{l}\text { Escola Anna Nery } \\
\text { 25(spe). } 2021 .\end{array}$ & Português & $\begin{array}{c}\text { Refletir sobre o } \\
\text { desenvolvimento } \\
\text { do pensamento } \\
\text { crítico no ensino } \\
\text { de enfermagem } \\
\text { em tempos de } \\
\text { pandemia de } \\
\text { Covid-19. }\end{array}$ & $\begin{array}{c}\text { Estudo teórico-reflexivo que } \\
\text { elencou duas categorias: } \\
\text { A importância do pensamento } \\
\text { crítico na educação de } \\
\text { enfermagem e Inovação para } \\
\text { estimular o pensamento crítico. } \\
\text { O cenário de pandemia } \\
\text { assumiu um caráter } \\
\text { pedagógico, porque ensinou } \\
\text { sobre a necessidade de } \\
\text { mudanças nos modos de fazer } \\
\text { atenção, gestão e pesquisa, bem } \\
\text { como sinaliza para o campo da } \\
\text { educação em saúde a } \\
\text { necessidade de adaptação dos } \\
\text { processos de ensino e } \\
\text { aprendizagem à realidade das } \\
\text { condições de vida dos } \\
\text { estudantes. O aspecto cognitivo } \\
\text { do pensamento crítico é a } \\
\text { habilidade metacognitiva de } \\
\text { automonitoramento e } \\
\text { autorreflexão. Para desenvolver } \\
\text { essa habilidade, os estudantes } \\
\text { devem ser desafiados em sua } \\
\text { aprendizagem, incluindo-se } \\
\text { nesse ensino as propostas de } \\
\text { atividades baseadas nos } \\
\text { problemas. }\end{array}$ & $\begin{array}{l}\text { Espera-se despertar nos } \\
\text { formadores a reflexão em } \\
\text { torno do compromisso } \\
\text { com o ato de ensinar em } \\
\text { tempos de mudanças, } \\
\text { adaptando suas práticas } \\
\text { pedagógicas com } \\
\text { criatividade, inovação } \\
\text { tecnológica e } \\
\text { desenvolvimento do } \\
\text { pensamento crítico nos } \\
\text { estudantes. }\end{array}$ \\
\hline $\begin{array}{l}\text { Mediações } \\
\text { pedagógicas de } \\
\text { ensino não } \\
\text { formal da } \\
\text { enfermagem } \\
\text { durante a } \\
\text { pandemia de } \\
\text { COVID-19 }\end{array}$ & $\begin{array}{l}\text { Prata, J.A., } \\
\text { Mello, A.S., } \\
\text { Costa e Silva } \\
\text { F.V. \& Faria, } \\
\text { M.G.A. }\end{array}$ & $\begin{array}{c}\text { Rev Bras Enferm. } \\
2020\end{array}$ & Inglês & $\begin{array}{c}\text { Relatar a } \\
\text { experiência do } \\
\text { desenvolvimento } \\
\text { de mediações } \\
\text { pedagógicas em } \\
\text { Ambiente } \\
\text { Virtual de } \\
\text { Aprendizagem } \\
\text { implementadas } \\
\text { em uma } \\
\text { faculdade de } \\
\text { enfermagem } \\
\text { durante a } \\
\text { pandemia de } \\
\text { COVID-19. }\end{array}$ & $\begin{array}{c}\text { A concepção, } \\
\text { operacionalização e } \\
\text { implementação do curso foi } \\
\text { fruto de um trabalho coletivo } \\
\text { que culminou em um processo } \\
\text { de ensino não formal, virtual e } \\
\text { problematizador, o qual } \\
\text { alcançou taxa de participação } \\
\text { de } 82 \% \text { dos educandos } \\
\text { inscritos. }\end{array}$ & $\begin{array}{c}\text { Mesmo em tempos de } \\
\text { isolamento social, o curso } \\
\text { promoveu a aprendizagem } \\
\text { colaborativa } \\
\text { de conhecimentos acerca } \\
\text { da COVID-19, estreitando } \\
\text { as relações entre docentes } \\
\text { e educandos. } \\
\text { Ressalta-se a possibilidade } \\
\text { de realizar atividades a } \\
\text { distância baseadas em } \\
\text { propostas } \\
\text { metodológicas sólidas que } \\
\text { contrariam a lógica } \\
\text { conteudista } \\
\text { frequentemente observada } \\
\text { na } \\
\text { Educação a Distância. }\end{array}$ \\
\hline $\begin{array}{l}\text { Efeitos do S-PBL } \\
\text { na Clínica de } \\
\text { Enfermagem da } \\
\text { Maternidade } \\
\text { Pratique em } \\
\text { Atitude de } \\
\text { Aprendizagem, } \\
\text { Metacognição, } \\
\text { e Pensamento } \\
\text { Crítico em } \\
\text { Estudantes de } \\
\text { Enfermagem: } \\
\text { Um design quase } \\
\text { experimental }\end{array}$ & Son, H.K. & $\begin{array}{l}\text { Int. J. Environ. } \\
\text { Res. Public } \\
\text { Health. } 2020 .\end{array}$ & Inglês & $\begin{array}{c}\text { Investigar o e } \\
\text { efeitos simulação } \\
\text { da } \\
\text { Aprendizagem } \\
\text { Baseada em } \\
\text { Problemas (S- } \\
\text { PBL), na prática } \\
\text { clínica de } \\
\text { enfermagem em } \\
\text { maternidade, na } \\
\text { atitude de } \\
\text { aprendizagem, } \\
\text { metacognição e } \\
\text { pensamento } \\
\text { crítico nos } \\
\text { alunos de } \\
\text { enfermagem. }\end{array}$ & $\begin{array}{c}\text { Foi utilizado um projeto de } \\
\text { pré-teste-pós-teste de grupo de } \\
\text { controle quase } \\
\text { experimental. Estudantes de } \\
\text { enfermagem foram alocados } \\
\text { aleatoriamente para o grupo } \\
\text { controle ( } n=31 \text { ) e o grupo } \\
\text { experimental ( } n=47 \text { ). Os } \\
\text { alunos do grupo de controle } \\
\text { participaram de um estágio } \\
\text { clínico tradicional na } \\
\text { maternidade por uma semana, } \\
\text { enquanto os alunos do grupo } \\
\text { experimental participaram de } \\
\text { S-PBL por uma semana. Os } \\
\text { alunos do grupo experimental } \\
\text { foram treinados em pequenos } \\
\text { grupos por meio de um } \\
\text { simulador de parto } \\
\text { (Gaumard }{ }^{\circledR} \text { Noelle }{ }^{\circledR} \text { S554.100, } \\
\text { Miami, EUA) com base em um } \\
\text { cenário padronizado } \\
\text { relacionado à assistência } \\
\text { obstétrica. A atitude de } \\
\text { aprendizagem, metacognição e } \\
\text { pensamento crítico dos alunos } \\
\text { foram então medidos por meio } \\
\text { de um questionário de }\end{array}$ & $\begin{array}{l}\text { O S-PBL foi considerado } \\
\text { uma estratégia eficaz para } \\
\text { melhorar a transferência de } \\
\text { aprendizagem dos } \\
\text { estudantes de } \\
\text { enfermagem. Assim, o S- } \\
\text { PBL que reflete diversas } \\
\text { situações clínicas é } \\
\text { recomendado para } \\
\text { aprimorar a formação em } \\
\text { enfermagem em saúde } \\
\text { materna. }\end{array}$ \\
\hline
\end{tabular}




\begin{tabular}{|c|c|c|c|c|c|c|}
\hline & & & & & $\begin{array}{l}\text { autoavaliação. Em comparação } \\
\text { com o grupo de controle, a } \\
\text { diferença pré-pós na atitude de } \\
\text { aprendizagem e pensamento } \\
\text { crítico aumentou } \\
\text { significativamente }(p<0,01) \text { no } \\
\text { grupo experimental. }\end{array}$ & \\
\hline $\begin{array}{c}\text { Estado da arte } \\
\text { sobre o ensino de } \\
\text { Enfermagem e os } \\
\text { desafios do uso } \\
\text { de tecnologias } \\
\text { remotas em } \\
\text { época de } \\
\text { pandemia do } \\
\text { corona vírus. }\end{array}$ & Bezerra, I.M.P. & $\begin{array}{c}\text { J Hum Growth } \\
\text { Dev. } 2020 .\end{array}$ & Português & $\begin{array}{c}\text { Descrever o } \\
\text { estado da arte } \\
\text { sobre o ensino de } \\
\text { enfermagem e os } \\
\text { desafios do uso } \\
\text { de tecnologias } \\
\text { remotas em } \\
\text { época de } \\
\text { pandemia do } \\
\text { Corona vírus. }\end{array}$ & $\begin{array}{l}\text { Estudo reflexivo que evidencou } \\
\text { que os efeitos da pandemia no } \\
\text { contexto educacional sobretudo } \\
\text { no âmbito da Enfermagem, } \\
\text { implicam numa mudança de } \\
\text { atitude dos gestores, docentes e } \\
\text { discentes, a fim de reformular } \\
\text { as práticas de ensino em } \\
\text { práticas inovadoras que } \\
\text { permitam criticidade, reflexão, } \\
\text { diálogo, vínculo e interação. } \\
\text { Entretanto, à medida que se } \\
\text { abriu para discussões sobre } \\
\text { novas formas de } \\
\text { ensinar mediadas pela } \\
\text { inovação, pode-se dizer que } \\
\text { esse será o maior impacto da } \\
\text { pandemia para o ensino: a } \\
\text { contribuição das novas } \\
\text { tecnologias de informação e } \\
\text { comunicação no processo } \\
\text { ensino aprendizagem para } \\
\text { formação em saúde, assim } \\
\text { como a reflexão sobre a } \\
\text { educação à distância e seus } \\
\text { conceitos, diferenciando-a } \\
\text { dos conceitos de metodologia } \\
\text { remota e o uso das tecnologias. }\end{array}$ & $\begin{array}{c}\text { No ensino da enfermagem, } \\
\text { a discussão relacionada ao } \\
\text { uso de } \\
\text { tecnologias remotas em } \\
\text { sala de aula sempre foi um } \\
\text { ponto de debate. } \\
\text { Entretanto, } \\
\text { com a necessidade da } \\
\text { inclusão dessas } \\
\text { ferramentas para a } \\
\text { continuidade de } \\
\text { aulas no formato não } \\
\text { presencial decorrente da } \\
\text { estratégia do isolamento } \\
\text { social motivada pela } \\
\text { pandemia do COVID-19, } \\
\text { pode oportunizar a se ter } \\
\text { um novo olhar } \\
\text { sobre o assunto e que } \\
\text { talvez com esse momento } \\
\text { vivido se haja } \\
\text { oportunidade de } \\
\text { ampliar o debate sobre uso } \\
\text { dessas metodologias } \\
\text { remotas no ensino em } \\
\text { saúde, buscando uma } \\
\text { reflexão sobre a interação } \\
\text { destas com os demais } \\
\text { métodos de ensino já } \\
\text { implementados. }\end{array}$ \\
\hline
\end{tabular}

Fonte: Dados da pesquisa (2021).

\section{Discussão}

Após a análise e síntese dos estudos selecionados surgiram duas categorias principais: Utilização de metodologias ativas, estratégias de ensino e tecnologias no contexto de pandemia; e Desafios e obstáculos da modalidade remota para o ensino em Enfermagem durante a pandemia.

Categoria 1: Utilização de metodologias ativas, estratégias de ensino e tecnologias no contexto de pandemia

A pandemia pelo COVID-19 trouxe diversas mudanças no cenário educacional mediante o contexto de distanciamento social, como é colocado por Riegel et al (2021) em seu estudo de reflexão que as instituições de ensino precisaram incorporar novos projetos de aprendizagem com uma abordagem inovadora em seus currículos com intenção de substituir o ensino presencial.

Bezerra (2020) corrobora com esse achado e acrescenta que a continuidade das aulas através de ambientes remotos, estimulou o desenvolvimento de novos modelos de ensino que incluem tecnologias de informação e comunicação (TIC), fazendo com que as práticas tradicionais fossem repensadas. A autora acredita que o uso das novas tecnologias com a utilização de metodologias ativas possibilita um ensino de caráter multissensorial, motivador, dinâmico e flexível, que estimula a reflexão e ainda gerador da socialização do conhecimento.

Para Vieira e Santos (2020), no contexto do distanciamento social, a metodologia ativa é a estratégia pedagógica que mais incentiva o desenvolvimento do aluno, auxiliando na compreensão de aspectos cognitivos, socioeconômicos, afetivos, políticos e culturais. Além disso, ela é capaz de aperfeiçoar a autonomia individual. Atrelado a isso, de acordo com Riege et al 
(2021), o emprego de MA configura-se em um dos caminhos para que professores possam ajudar seus alunos na construção do pensamento crítico.

Dentre as ferramentas tecnológicas mais utilizadas na pandemia, dois estudos destacam o Ambiente Virtual de Aprendizagem (AVA) como meio facilitador no processo de ensino-aprendizagem, onde as atividades realizadas sob uma perspectiva problematizadora impactam rompendo os paradigmas da educação tradicional, refletindo em mudanças no modo de ensinar e aprender no ciberespaço, além de mudanças no relacionamento entre docente e discente (Silva et al, 2021; Prata et al, 2020).

No contexto da emergência mundial de saúde pública, pelo vírus da COVID-19, as mudanças no cenário educacional são necessárias de modo que ambientes de aprendizagem digital tem se demonstrado um importante aliado pedagógico, tecnológico e inovador, nas práticas de simulações realísticas através de serious game (Nascimento et al., 2021).

Riege et al (2021) destaca em sua pesquisa, sobre as diferentes estratégias e metodologias de ensino capazes de acelerar a capacidade dos discentes de pensar criticamente, dentre elas: a simulação, discussões clínicas com base em casos e dramatização, discussões em grupo e prática clínica. Para ele, nos projetos de ensino em enfermagem, os docentes devem incluir propostas de atividades baseadas nos problemas da prática clínica cotidiana, permitindo que os alunos pensem e raciocinem clinicamente para a tomada de decisões.

Com a construção de uma situação problema que proporciona uma reflexão crítica onde o aluno busca o conhecimento, caracteriza-se um dos tipos de metodologia ativa o Team Based Learning (TBL), onde na busca pela solução do problema aproxima cada vez mais o raciocínio teórico e prático. Outra estratégia eficaz, é a utilização da simulação realística das habilidades clínicas, no qual os alunos interagem e expressam suas opiniões em um ambiente seguro e controlado, preparandoos para a desafiadora realidade prática dos serviços de saúde (Riege et al, 2021).

A simulação clínica se destaca, nesse sentido, como uma estratégia de ensino que, além de favorecer a segurança do paciente e melhorar a satisfação do aluno, por aplicar diversas situações clínicas, auxilia na segurança e pensamento e julgamento crítico do mesmo, sobretudo através do desenvolvimento de habilidades e competências (Boostel et al., 2021).

Estudo realizado por Canever et al., (2021) acrescenta ainda que a aprendizagem baseada em simulação possui um impacto positivo na formação do acadêmico de Enfermagem, pois diminui níveis de ansiedade, aumenta envolvimento com aprendizagem e autoconfiança no aprendizado.

Ainda, no tocante da problematização e simulação realística, Son (2020) aborda em seu estudo a aplicação da Simulação de aprendizagem baseada em problemas (S-PBL) que é um método no qual os alunos de enfermagem experimentam o processo de resolução de problemas de enfermagem através de interações com um simulador de paciente humano em um ambiente com características clínicas semelhantes à realidade. $\mathrm{O}$ autor sugere que as faculdades de enfermagem utilizem o S-PBL no processo de aprendizagem para que os alunos possam fortalecer sua atitude de aprendizagem, metacognição e pensamento crítico em sua educação prática de enfermagem.

Pito Alexandre $e$ Nunes (2020) utilizaram a abordagem baseada em problemas para auxiliar na formação de estudantes de enfermagem na disciplina de Vigilância em Saúde, problematizando contextos epidemiológicos como a pandemia por COVID-19 e epidemia de sarampo, de modo que essa abordagem educacional contribuiu para o preparo dos alunos diante de situações emergentes e reemergentes da vida em sociedade.

Nesse sentido, o uso dessas ferramentas no ensino-aprendizagem da enfermagem, deve estabelecer um processo pedagógico mais amplo, resultante de reflexões teóricas e de competências dialógicas do enfermeiro enquanto educador e com a incorporação de práticas inovadoras estimulando o aluno para a criticidade, reflexão, diálogo, vínculo e interação; características estas que fazem parte de uma formação que objetiva a mudança de paradigma, para a transformação e não apenas a transmissão do conhecimento (Bezerra, 2020). 
Por fim, a pandemia de Covid-19 nos mostrou que além da tecnologia da informação é necessário o desenvolvimento de diferentes métodos e modelos de ensino. É preciso ter disposição e interesse para aplicá-los e aprender nas práticas do processo ensino/aprendizagem, como também para enfrentar um cenário de constantes mudanças, deixando a zona de conforto e inovando em metodologias de ensino, atrelado ao desenvolvimento das ferramentas virtuais, a fim de garantir o desenvolvimento das competências essenciais à prática do enfermeiro (Riege et al, 2021).

Categoria 2: Desafios e obstáculos da modalidade remota para o ensino em enfermagem durante a pandemia

No momento atual, referente à pandemia por COVID-19, na qual se acelerou a adoção de tecnologias no ensino superior, faz-se necessário esclarecer as diferenças entre ensino remoto emergencial e intencional, e ensino a distância (EaD), conforme abordado por Lira et al., (2020). O primeiro, vem sendo utilizado há anos em situações de crise, e admite caráter temporário e o cenário é o mesmo: o professor cria suas aulas e faz sua intermediação com os alunos através da tecnologia. Já o segundo, há a intencionalidade centrada no aprendizado, com um processo organizacional, aumentando a qualidade de ensino.

O EaD, por sua vez, não possui interação entre tutor e aluno, pois as aulas são gravadas, e não existe a figura do professor, já que as aulas são feitas sob encomenda. Essa modalidade é contrária à formação dos cursos de graduação em Enfermagem, pela necessidade de contato humano e presencial para a qualidade do ensino, sendo um desafio atual em meio ao cenário de ensino (Lira et al., 2020).

Em contrapartida, Scorsolini-Comin et al. (2020) realizaram um estudo de reflexões acerca do ensino a distância nos cursos de Enfermagem, apresenta argumentos que ressaltam a importância de melhores discussões acerca do tema além do cenário de pandemia, de modo que a distância também surge como uma forma de adaptação a um modelo de isolamento e distanciamento social. No entanto, reforça que os conselhos de classe devem acompanhar esse cenário, para que elementos essenciais da formação não sejam perdidos, como o contato para o cuidado, corporeidade e interação face a face.

De uma maneira geral, há sempre desafios no processo de ensino-aprendizagem. Isso se dá porque os currículos universitários estão cada vez mais complexos e incorporados a tecnologia e assuntos repartidos e especializados, que levam à necessidade de reflexão de metodologias utilizadas nessa formação (Sobral et al., 2019).

No que tange os desafios profissionais da utilização das Metodologias Ativas (MA), um estudo trouxe que, os docentes que vivem esse processo devido o isolamento social pela COVID-19, demonstram que a utilização de meios on-line, como salas virtuais e aplicativos, para o ensino de enfermagem é uma tarefa desafiadora por demandar conhecimento tecnológico do docente, domínio e recursos tecnológicos do estudante e do professor (Silva et al., 2021).

Quanto ao acesso aos materiais tecnológicos, pode ser um impeditivo de continuidade de estudo, onde pode não ser acessível a todos, pois não se pode negar que apesar da popularização e avanços do uso do computador e do celular, o acesso à internet não é universal, infelizmente. E esta é uma desigualdade que foi fortalecida devido às atuais circunstâncias, onde há maior vulnerabilidades econômicas e sociais (Silva et al., 2021).

A cultura digital acompanha uma característica evolutiva, que se faz necessária com as características do ensino remoto emergencial. O celular está expressivamente presente na rotina dos indivíduos, mais ainda, nesse cenário de pandemia, tanto para trabalho, comunicação e atualizações, como também é uma ferramenta para o ensino a distância. Desta forma, o ensino em ambiente virtual pode ser visto como uma maneira mais autônoma, devendo ter um compromisso com si e um bom planejamento, devido às várias demandas em meio virtual. Essa modalidade também estimula a curiosidade e resolução de desafios, o que é imprescindível para prática profissional (Silva et al., 2021).

Acrescenta-se a esse cenário, o estresse gerado pelo excesso de informação, somando-se a baixa confiança nas atividades a distância para a produção do conhecimento, além do aumento de atividades escolares que pode ser um precursor 
para transtornos como ansiedade. Porém, é necessário avaliar os impactos positivos das várias ferramentas que estão disponíveis em meio virtual como forma de auxiliar a prática profissional do futuro enfermeiro (Silva et al., 2021; Bezerra, 2020).

Quanto às habilidades cognitivas, uma das estratégias para desenvolver o pensamento crítico nos estudantes é permitir que eles participem ativamente do seu processo de aprendizagem. Os docentes devem propor questões que estimulem as habilidades de pensar e que exijam a interpretação, análise minuciosa, evidências sólidas e avaliação. Além disso, os professores precisam demonstrar essa habilidade de pensamento crítico no seu agir docente, com isso, destaca-se a importância de os professores desenvolverem o pensamento crítico em si para estarem aptos a ensinar tais habilidades (Riegel et al., 2021).

Em relação ao pensamento crítico para estudantes, trata-se de uma preocupação antiga dos docentes em Enfermagem, já que se refere a um conceito complexo, com atividades complexas e processos mentais difíceis de medir e descrever, de modo que, de acordo com Rufino et al., (2020), configuram-se um julgamento intencional e autorregulável, resultado da interpretação, análise, avaliação e inferência, que está associado também ao conhecimento adquirido.

Quanto aos docentes nesse processo, Lacerda et al. (2019) ressaltam que o principal desafio é a formação permanente dos mesmos, bem como o apoio institucional para o preparo de cenários bem delineados, que permite o estudante a entrar na realidade simulada e avaliar diferentes aspectos. Como recomendação, destacam a necessidade dos cursos de graduação e pósgraduação analisarem os melhores recursos aplicados à realidade loca, para aplicação de metodologia ativa.

Para muitos discentes o uso das metodologias ativas é um desafio, pois transpassa sob uma reflexão do ensino à distância na área da enfermagem e nos demais cursos da área da saúde, entretanto, à medida que se instaurou o uso de novas metodologias no processo de ensino, é possível observar que tiveram grande impacto no processo de aprendizagem, tornando o semelhante à prática cotidiana, e fazendo do ensino mais atrativo e lúdico (Bezerra, 2020).

Sendo assim, os maiores desafios da utilização das metodologias ativas estão ligados à disponibilidade de aplicação pelo professor em sala virtual, e dos estudantes em acompanhar as aulas, que podem estar atrelados ao acesso ou dificuldade à internet e aos meios eletrônicos, além do estresse e ansiedade envolvidos.

\section{Considerações Finais}

Desta forma, é possível observar que a utilização das metodologias ativas é um facilitador do processo de ensino e aprendizagem, e vem ganhando destaque devido o ensino remoto pela pandemia. É notório que o tema é uma crescente entre o meio acadêmico, pois envolve discentes e docentes, que são peças fundamentais para aplicação e melhoria da metodologia a ser utilizada em sala de aula virtual.

A escolha pelo tipo de metodologia fica a critério do professor de acordo com a disponibilidade e participação da turma. Porém, é possível afirmar que as metodologias ativas, estas que colocam o aluno no centro do aprendizado corrobora para um melhor processo de ensino, pois assim há uma quebra com o modelo tradicional que por vezes o discente fica condicionado a reter informações.

Visualizando o cenário educacional, ainda enfrentando o distanciamento social, é importante que os docentes tentem se manter atualizados e disponíveis a entender e aplicar as melhores ferramentas de tecnologia da informação e comunicação, em sala virtual. No que tange a formação em enfermagem, o uso dessas ferramentas, são imprescindíveis para auxiliá-lo na prática futura, pois há diversas formas de simular técnicas e situações-problemas que ajudem o aluno a pensar na melhor assistência.

Entretanto, considerando-se que este estudo se utilizou de registros na literatura, e a importância dessa temática sobretudo no cenário de ensino remoto emergencial, sugere-se que sejam realizadas maiores pesquisas que avaliem o impacto das metodologias ativas na nova geração de profissionais atuantes, de modo que possa melhorar as evidências disponíveis atualmente acerca do objeto de estudo. 


\section{Referências}

Bezerra, I. M. P. (2020). Estado da arte sobre o ensino de Enfermagem e os desafios do uso de tecnologias remotas em época de pandemia do corona vírus. 30(1):141-147. http://doi.org/10.7322/jhgd.v30.10087.

Boostel, R. Bortolato-Major, C. Silva, N. O. Vilarinho, J. O. V. Fontoura, A. C. O. B. \& Felix, J. V. C. (2021). Contribuições da simulação clínica versus prática convencional em laboratório de enfermagem na primeira experiência clínica. Escola Anna Nery 25(3). https://doi.org/10.1590/2177-9465-EAN-2020-0301.

Canever, B. P. Sanes, M. S. Oliveira, S. N. Magalhães, A. L. P. Prado, M. L. \& Costa, D. G. (2021). Metodologias ativas no cateterismo periférico venoso: desenvolvimento de habilidades com simulador de baixo custo. Escola Anna Nery 25(1). https://doi.org/10.1590/2177-9465-EAN-2020-0131.

de Sousa Júnior, J. H., Raasch, M., Soares, J. C., \& de Sousa, L. V. H. A. (2020). Da Desinformação ao Caos: uma análise das Fake News frente à pandemia do Coronavírus (COVID-19) no Brasil. Cadernos de Prospecção, 13(2 COVID-19), 331.

Gil, A. A. G. (2010). Como elaborar projetos de pesquisa. Ed Atlas. ISBN: 8522458235, 9788522458233.

Lacerda, C. S. Sá, S. P. C. Braga, A. L. S. Balbino, C. M. \& Silvino, Z. R. (2019). Simulação como metodologia ativa para a educação dos estudantes em enfermagem: revisão integrativa. Online Braz J Nurs;19(2).

Lira, A. L. B. C. Adamy, E. K. Teixeira, E. \& Silva, F. V. (2020). Educação em enfermagem: desafios e perspectivas em tempos da pandemia COVID-19. Rev Bras Enferm. Vol. 73(Suppl 2): e20200683. http://dx.doi.org/10.1590/0034-7167-2020-0683.

Macedo, K. D. D. S., Acosta, B. S., Silva, E. B. D., Souza, N. S. D., Beck, C. L. C., \& Silva, K. K. D. D. (2018). Metodologias ativas de aprendizagem: caminhos possíveis para inovação no ensino em saúde. Escola Anna Nery. 22.

Nascimento, K. G. Ferreira, M. B. G. Felix, M. M. S. Nascimento, J. SG., Chavaglia, S. R. \& Barbosa, M. H. (2021). Efetividade do serious game para a aprendizagem na enfermagem: revisão sistemática. Rev Gaúcha Enferm.;42:e20200274. https://doi.org/10.1590/1983-1447.2021.20200274.

Oliveira, Z. M., de Freitas, L. M. A., dos Santos, N. C. N., Dias, J. A. A., de Freitas, M. D. C. A., \& Oliveira, T. M. (2020). Estratégias para retomada do ensino superior em saúde frente a COVID-19. Revista Enfermagem Atual In Derme, 93, e020008-e020008.

Prata, J. A., Mello, A. S., Costa e Silva F. V. \& Faria, M. G. A. (2020). Mediações pedagógicas de ensino não formal da enfermagem durante a pandemia de COVID-19. Rev Bras Enferm.;73(Suppl 2): http://dx.doi.org/10.1590/0034-7167-2020-0499 e20200499.

Pito Alexandre, L. B. S. \& Nunes, M. I. (2020). Problematização sobre a pandemia da COVID-19 como auxílio na formação de enfermeiras/os. Revista Nursing, , Vol. 23 (266): 4294-4300. https://doi.org/10.36489/nursing.2020v23i266p4294-4307.

Scorsolini-Comin, F. Melo, L. P, Rossato, L. \& Gaia, R. S. P. (2020). Educação a distância na formação em enfermagem: reflexões sobre a pandemia da COVID19. Rev baiana enferm, Vol.34:e36929.

Riegel, F., Martini, J. G., Bresolin, P., Mohallen, A. G. C., \& Nes, A. A. G. (2021). Desenvolvendo o pensamento crítico no ensino de Enfermagem: um desafio em tempos de pandemia de Covid-19. Esc. Anna. Nery. 25.

Rufino, C. G. et al. (2020). Pensamento crítico e as estratégias de ensino para docentes do curso de graduação em enfermagem. Rev enferm UERJ, Rio de Janeiro, 28:e41988. http://dx.doi.org/10.12957/reuerj.2020.41988.

Silva, C. M. Toriyama, A. C. M., Claro, H. G., Borghi, C. A., Castro, T. J. \& Salvador, P. I. C. A. (2021) Pandemia da COVID-19, ensino emergencial a distância e Nursing Now:desafios à formação em enfermagem. Rev Gaúcha Enferm. 42(esp):e20200248. https://doi.org/10.1590/1983-1447.2021.20200248.

Sobral, J. P. C. P. Viana, M. E. R. Lívio, T. A. Santos, A. G. Costa, B. G. S. \& Rozendo, C. A. (2020). Metodologias ativas na formação crítica de mestres em enfermagem. Rev Cuid. Vol. 11(1): e822. http://dx.doi.org/10.15649/cuidarte.822.

Son, H. K. (2020). Efeitos do S-PBL na Clínica de Enfermagem da Maternidade Pratica em Atitude de Aprendizagem, Metacognição, e Pensamento Crítico em Estudantes de Enfermagem: Um design quase experimental. Int. J. Environ. Res. Public Health. 17, 7866; 10.3390/ijerph17217866.

Ursi, E. S. (2005). Prevenção de lesões de pele no perioperatório: revisão integrativa da literatura. p. 130. Dissertação (Mestrado em Enfermagem) - Ribeirão Preto: Universidade de São Paulo, Escola de Enfermagem de Ribeirão Preto.

Vieira, T. D. G. F., \& Santos, M. L. S. C. dos. (2020). Pedagogical strategies and use of active methodologies in undergraduate Nursing in times of Coronavirus pandemic - COVID - 19. Research, Society and Development, 9(11), e2759119749. https://doi.org/10.33448/rsd-v9i11.9749 